\title{
MORAL, ÉTICA E DIREITO
}

\section{Orlando Luiz Zanon Junior ${ }^{1}$}

Resumo: O presente texto propõe novos conceitos operacionais para Moral e Ética, de modo a clarificar a compreensão da moralidade política e, assim, viabilizar uma leitura mais adequada, nos aspectos descritivos e normativos, de sua confluência com o Direito.

Palavras-chaves : Moral. Ética. Teoria do Direito.

\section{INTRODUÇÃO}

O tema referente ao relacionamento entre Moral, Ética e Direito é um dos mais complexos e polêmicos entre os Juristas. Entretanto, trata-se de problema teórico cuja resolução é imprescindível para construção de um novo modelo disciplinar adequado para Ciência Jurídica, que permita a superação da crise paradigmática do Positivismo Jurídico, sem retrocesso ao antigo padrão do Jusnaturalismo. Com efeito, a resolução do tema em tela serve de base filosófica para definição de questões tormentosas, como a da legitimidade política e a da relação entre poder, decisão e justiça.

Para os jusnaturalistas, vigorava a ideia metafísica de que era possível encontrar elementos morais na natureza (algo como uma espécie de morons ou de jusnaturons, ao lado de prótons, nêutrons e elétrons), através do exercício da boa razão, os quais serviam de parâmetro superiores para aferição da legitimidade e da validade dos preceitos legais e decisões jurisdicionais. Logicamente que a ilusão metafísica dos jusnaturalistas não encontra

1 Juiz de Direito. Doutor em Ciência Jurídica pela UNIVALI. Dupla titulação em Doutorado pela UNIPG (Itália). Mestre em Direito Pela UNESA. Pós-graduado pela UNIVALI e pela UFSC. E-mail: orlandozanon@hotmail.com 
mais aceitação no seio da Comunidade de Juristas, salvo para alguns acadêmicos isolados.

De outro lado, a tese juspositivista da separação entre moralidade e juridicidade foi severamente criticada, haja vista que não reflete a realidade do fenômeno jurídico (aspecto descritivo da ciência) e tampouco atende à finalidade institucional do Direito quanto à promoção de equidade e de justiça (aspecto prescritivo da ciência).

Então, o tema merece ser enfrentado, para viabilizar a construção de uma proposição pós-positivista apta a reger a Ciência Jurídica por considerável lapso de tempo, ao menos até posterior ruptura paradigmática.

Por fim, cabe esclarecer que este artigo derivou de estudos que resultaram na obra Teoria Complexa do Direito, a qual engloba o conteúdo ora apresentado, com eventuais modificações ${ }^{2}$.

\section{NOVOS CONCEITOS DE MORAL, ÉTICA E DIREITO}

Nesta primeira seção de texto, cabe propor novos conceitos operacionais para Moral e Ética, de modo a clarificar a compreensão da moralidade política e, assim, viabilizar uma leitura mais adequada, nos aspectos descritivos e normativos, de sua confluência com o Direito. Isto porque não há um acordo semântico entre os autores analisados acerca dos significados das duas referidas categorias, cabendo resolver tal problema antes de ingressar em uma proposição acerca da relação entre moralidade e juridicidade.

Por exemplo, entre os juspositivistas, Kelsen abordava a Moral sob o enfoque da capacidade de previsibilidade e de reforço de seus postulados, como uma ordem social altamente variável espacial e temporalmente, cujas sanções não eram institucionalizadas, possuindo força meramente transcendental. A Ética, de outro lado, seria o nome dado ao campo científico de

2 A referência da obra citada é: ZANON JUNIOR, Orlando Luiz. Teoria Complexa do

Direito. CEJUR: Florianópolis, 2013. 
estudos acerca da moralidade, como uma ciência do comportamento social não juridicizado (KELSEN, 2006, p. 67 e 77).

No lado dos pós-positivistas, Dworkin difere os dois conceitos de acordo com a abordagem coletiva do primeiro e individualista do segundo, no sentido de que a Moral é composta pelos argumentos sobre qual o tratamento que uma pessoa deve corretamente dispensar às outras, de modo a harmonizar a convivência em comunidade da melhor maneira possível, enquanto, de outro lado, a Ética foca a perspectiva dos julgamentos pessoais que devem ser feitos por cada um para conduzir sua vida com o objetivo de atingimento de resultados bons para si, de forma virtuosa. Sem embargo, para o referido autor, "an ethical judgment makes a claim about what people should do to live well: what they should aim to be and achieve in their own lives. A moral judgment makes a claim about how people must treat other people" (DWORKIN, 2011, p. 25).

Como a intenção aqui não é efetuar um levantamento de como os doutrinadores têm diferenciado ambas categorias, cabe apresentar conceitos operacionais para cada uma que possam se articular melhor com as demais premissas adotadas e, assim, auxiliar a proposição de superação do Juspositivismo a ser elaborada na seção seguinte deste trabalho.

Com este intuito, entende-se como Moral a escala de valores de cada pessoa, voltada ao direcionamento daquilo que é certo ou errado (justo ou injusto), de acordo com seu conhecimento adquirido, de modo a orientar as suas deliberações. Tal abordagem da moralidade é amplamente subjetiva e, assim, variável no espaço e no tempo, porquanto diz respeito às opiniões de determinada pessoa acerca do que é correto ou incorreto de se fazer, de acordo com a carga axiológica que adquiriu até o momento.

Assim, a análise moral acerca de determinado assunto tende consideravelmente a ser diferente com relação a cada pessoa e, mesmo quanto ao mesmo indivíduo, varia no tempo, de acordo com sua gradual aquisição (ou perda) de conheci- 
mento, ou mesmo segundo seu estado emocional ou psicológico em geral. Sobre esta ótica, as experiências de vida particulares, absorvidas ao longo da existência em uma Sociedade amplamente heterogênea e complexa, influenciam determinantemente os contornos da Moral, que é altamente flexível e fluída, relevando sua difícil investigação e aferição.

A Ética, de outro lado, consiste no conjunto de parâmetros valorativos convergentes em determinado grupo de pessoas ou comunidade individualmente identificável, de modo a orientar e delimitar as deliberações tomadas perante o agrupamento. Assim, a eticidade reflete um passo adiante no progresso civilizatório, na medida em que a formação de grupos sociais implica a definição das margens de convergência de critérios morais, de modo a tornar claras as ponderações axiológicas de determinado conjunto de pessoas acerca do que é certo e errado.

Com efeito, a partir do momento em que as interações entre agrupamentos dão margem a associações e comunidades, as pessoas gradualmente vão expondo seus pontos de vista acerca da moralidade e, através de meios consensuais ou impositivos, vão sendo estabelecidos quais os critérios morais que devem prevalecer para fins de harmonizar a convivência e otimizar as atividades úteis da respectiva coletividade, tornando mais transparentes quais os valores que lhes são caros e as consequências de determinadas condutas. A fixação destas margens de convergência acerca de parâmetros morais denota o nascimento da Ética, que está relacionada com os valores predominantes para determinado grupo social, de modo consensual ou mesmo autoritário, cuja aferição é muito mais fácil em razão da projeção comunicativa proporcionada pela difusão de tal apreciação axiológica dentro do grupo e perante aqueles que com ele se relacionam.

Importa referir, ainda, que o conceito operacional ora adotado não é plenamente compatível com o entendimento no sentido de que a Ética se caracteriza como "o conjunto dos melhores princípios, valores e imperativos sobre a conduta 
humana, após ter realizado pesquisas históricas e apresentado argumentos filosóficos" (DIMOULIS, 2006, p. 168). Isto porque os parâmetros éticos prevalecentes em determinado grupo social podem, eventualmente, ser fortemente contrários àqueles que outra comunidade entendem como adequados.

Como exemplo, pode-se mencionar uma hipotética comunidade cujos valores preponderantes recomendam a total submissão da mulher perante o homem, por ser considerada um gênero sexual impuro da raça humana, com base em certos valores influenciados pela ordem religiosa então vigente. Por certo que tal grupo social contraria a visão eticamente prevalecente no cenário ocidental, em que se concebe a igualdade de consideração e respeito entre pessoas de ambos os sexos. Assim, a Ética, apesar de sua maior irradiação do que a Moral, também não reflete um caráter universalista, embora alguns estudiosos e políticos estejam envidando esforços para promover o compartilhamento em âmbito mundial de determinados conjuntos de valores, de modo a otimizar a relação harmônica entre todos os povos da Terra (Ética mundial).

Nessa linha de raciocínio, os dois institutos dizem respeito ao direcionamento do que deve ou não ser feito, de acordo com a aferição axiológica daquilo que é correto e incorreto (justo ou injusto), com vistas a limitar a capacidade de deliberação, na medida que tendem a restringir certas condutas ao classificá-las como negativas, indignas, indevidas ou inadequadas. Porém, enquanto a Moral revela uma apreciação individual acerca do que é certo ou errado, a Ética representa a convergência de tais parâmetros de correção para um determinado grupo, maior ou menor, mediante um diálogo consensual construído ao longo do tempo, ou mesmo através da imposição de alguma força social prevalecente no respectivo agrupamento.

Assim, a diferença entre os dois conceitos é, na sua base, relacionada com o âmbito de difusão, haja vista que a primeira diz respeito ao indivíduo, enquanto a segunda dá um passo adiante, referindo-se aos pontos de convergência preponde- 
rantes para uma interação entre pessoas, pertencentes a um conjunto identificável. Daí que, enquanto a apreciação da Moral é dificultada pela sua limitação subjetiva, a percepção da Ética é amplamente facilitada pelo seu compartilhamento entre os membros de determinada comunidade, ainda que não necessariamente na forma escrita.

Cabe referir que os julgamentos morais e éticos influenciam, ainda que de forma inconsciente, as tomadas de decisões das pessoas, ainda que seja no sentido de justamente contrariar aquilo que entendem como certo. Por exemplo, não é incomum que uma pessoa, ao subtrair indevidamente os pertences de outra, entenda que sua conduta é moralmente inadequada, pois contrária àquilo que entende como valioso, e ainda eticamente reprovável, porquanto incompatível com os ditames compartilhados intersubjetivamente em comunidade, embora mesmo assim proceda por crer, por exemplo, que não será descoberta nem punida. Outrossim, quando se afirma que a Moral e a Ética influenciam e orientam a tomada de decisão, isto muito obviamente não significa que ambas sejam forças naturais que causem determinada conduta. Na verdade, como bem ressaltado pelos verbos empregados nesta exposição (influenciar e orientar), tais ordens sociais apenas ingressam como influxos na atividade avaliativa das pessoas, antes ou na eminência de agirem.

Importa ainda não olvidar que a moralidade, nos seus âmbitos moral e ético, não é uma ordem natural a ser descoberta pelo homem, mas sim uma construção artificial das pessoas, produzida culturalmente, de acordo com a carga de conhecimento de acumulam. No ponto, não é ocioso lembrar novamente a lição de Dworkin, no sentido de que não existem partículas morais (morons) ou jusnaturalísticas (jusnaturons) flutuando no espaço (floating out there), que possam ser captadas, além de prótons, nêutrons, elétrons e outros, para permitir a mera descoberta do que é certo ou errado (DWORKIN, 2011, p. 418).

Outrossim, a Moral e a Ética são produtos culturais, construídos para otimizar a tomada de deliberação pelas pessoas, de 
acordo com sua apreciação axiológica de como obter uma boa vida, para se conduzir ou não conforme tais critérios (afinal, ser imoral ou antiético é também uma opção, embora passível de reprovação social).

Especificamente quanto ao Direito, também não é verificável um consenso entre os Juristas, sendo necessário construir o respectivo conceito operacional.

Entre os juspositivistas, Kelsen focou sua resposta no caráter coativo, ao afirmar que se trata de uma ordem social diferente das demais justamente no ponto em que apresenta sanções institucionalizadas (KELSEN, 2006, p. 37). Porém, tal resposta é parcial, pois enfoca apenas um dos aspectos relevantes da discussão, consistente na imprescindível força para imposição das orientações normativas, haja vista que não decorrem naturalmente. Hart, de outro lado, focou a análise estrutural, ao estabelecer que se trata de um conjunto centralizado por Regras Jurídicas primárias e secundárias, com outros diversos elementos decisórios importantes na periferia do sistema, como os Princípios (HART, 2009, p. 128). Mas, tal abordagem foi derruída por Dworkin, que bem apresentou ser inviável se conceber o Direito como um grupo fixo de padrões deliberativos de algum tipo (DWORKIN, 2007, p. 35-36). Aliás, o último jurista mencionado, referiu claramente sua oposição "à ideia de que o 'direito' é um conjunto de padrões fixos de algum tipo" (DWORKIN, 2007, p. 119).

Do lado dos pós-positivistas, Alexy produziu um estudo específico sobre o tema, concluindo consistir num sistema de Normas que, concomitantemente, são formuladas com pretensão à correção, têm eficácia social global (ou ao menos possuem possibilidade de efeitos gerais), não são extremamente injustas e estão adequadas aos parâmetros de uma Norma fundamental pressuposta, cuja aplicação pode se apoiar em Princípios ou em outros argumentos normativos (ALEXY, 2009, p. 151). Mas tal conceito, ao incluir a Fórmula Radbruch, acaba por minar a importante herança positivista da obrigatoriedade de observância dos Textos Normativos, que representa o ganho 
principal sobre o Jusnaturalismo. Dworkin, por sua vez, focou sua análise na função social do instituto, ao afirmar que "o Direito é um empreendimento político, cuja finalidade geral, se é que tem alguma, é coordenar o esforço social e individual, ou resolver disputas sociais e individuais, ou assegurar a justiça entre os cidadãos e entre eles e seu governo, ou alguma combinação dessas alternativas" (DWORKIN, 2005, p. 239).

Diante de tal quadro teórico, importa construir um conceito operacional de Direito que seja completo e adequado à construção de uma nova matriz disciplinar, sem olvidar da contribuição dos autores acima expostos, porém focando na razão histórica que ensejou a própria construção artificial do instituto pela humanidade, mediante um enfoque cumulativamente realista (fidelidade descritiva) e normativista (funcionalidade do instituto).

Com tal duplo eixo em mente (descrição e prescrição), é possível verificar que existe uma intrínseca articulação entre a moralidade política e o Direito, no sentido de que ambos são intrinsecamente voltados à Decisão.

Elaborando a partir daí, pode-se afirmar que o Direito é, em verdade, uma especialização da Ética, no sentido de fixar no nível estatal os padrões decisórios a serem observados em Sociedade, bem como estabelecer as respectivas consequências, sejam elas promocionais, reparativas, punitivas ou quaisquer outras, a serem reforçadas por estruturas organizacionais especialmente designadas para tal finalidade (PECES-BARBA. FERNÁNDEZ. ASÍS, 2000, p. 19).

Outrossim, o Direito é um passo adiante da Ética, no sentido da institucionalização de padrões de conduta mediante a articulação da Sociedade com o Estado, nada vedando eventual sobreposição ou ampliação do sistema, mediante a criação de órgãos supranacionais e internacionais e sem prejuízos de influxos decorrentes do pluralismo normativo ou da transnacionalidade. 


\section{BREVÍSSIMA ABORDAGEM HISTÓRICA}

É possível ilustrar os conceitos operacionais antes expostos através de uma brevíssima abordagem histórica, baseada muito vagamente na ficção contratualista clássica, com algumas pitadas de realismo descritivo.

Imagine-se, a um, a situação hipotética de um homem isolado em determinado local, como uma ilha deserta e inacessível a outros. A sua sobrevivência perpassa pela harmonização apenas com o meio ambiente, de modo a afastar a utilidade da Ética e do Direito, embora a Moral (que consubstancia uma pauta axiológica pessoal) possa condicionar as decisões que tomará, ainda que seja para rejeitar aquilo internalizado como certo (reitera-se que agir imoralmente é uma opção). Todo o conhecimento dele estará focado em bem sobreviver, como é típico dos seres vivos (salvo se optar por mal viver, se assim quiser ou for forçado por falhas biopsicológicas), porém, não lhe será possível a discussão acerca de padrões de convivência, em razão da sua existência isolada de outros seres racionais.

A dois, avançando na história deste homem, conceba-o agora tendo que conviver com uma pessoa ou um grupo, de modo a ser necessário dividir recursos, definir sobre a reprodução e filhos, determinar tarefas e responsabilidades, conferir garantias de subsistência e, enfim, estabelecer disciplinas em todos os temas necessários à interação intersubjetiva, ainda que tais parâmetros de convivência sejam fixados apenas episodicamente ou gradualmente, na medida que os problemas aparecem. Cada um dos envolvidos possuí seus próprios critérios morais, porém, no desenrolar desta convivência, serão factualmente forçados a definir algumas áreas de convergência de padrões decisórios, seja mediante consenso, por imposição do mais forte ou qualquer outra forma de definição de tal uniformização valorativa (como de fato historicamente ocorreu). É então que surge a Ética, consistente justamente nesta fixação quanto às áreas de abrangência. Com esta delimitação do que é valorativamente 
certo ou errado, os membros do agrupamento podem conduzir suas condutas com maior previsibilidade quanto às decisões que tomarem, de modo que, acaso optem por desrespeitar os acordos intersubjetivos, devem estar preparados para eventuais consequências, como vergonha perante os demais, futuras negativas de negociação ou de reprodução, dentre muitas eventuais outras. Afinal, dado o caráter intersubjetivo dos ditames éticos, os demais integrantes do grupo podem modificar sua conduta com relação àqueles que são apanhados infringindo postulados socialmente importantes.

A três, importa ter em perspectiva a evolução gradual do relacionamento do grupo, ao longo das gerações, assumindo graus cada vez mais intensos de heterogeneidade e complexidade, mediante o aumento populacional, a divisão em grupos distintos, o advento de outros povos, o surgimento de lideranças políticas (autoritárias ou democráticas), o aperfeiçoamento das técnicas produtivas, o desenvolvimento do comércio, o acúmulo de uma carga cada vez maior de conhecimento, a gradativa especialização das funções, a divisão de tarefas e, enfim, todas as características que se exacerbaram ao longo do processo civilizatório. As modificações na forma de interação acabaram por transpor a capacidade organizacional da Ética, mesmo daqueles postulados valorativos já enraizados no costume da Sociedade, de modo a recomendar uma fixação mais segura das diretrizes sociais, ainda que mediante a criação de estruturas políticas específicas para produzir tais orientações (função legislativa), executar as políticas públicas (executivo) e, em caso de conflito, determinar quem tinha razão (atribuição judiciária). Sem embargo, "agir racionalmente implica tomar decisões, e as pessoas muitas vezes precisam fazê-lo em condições de profunda incerteza” (POSNER, 2011, p. 11). É então que surge o Direito, como um passo adiante da Ética, através do qual se delimitam quais as Fontes Jurídicas legítimas para tomada de Decisões em Sociedade. Com efeito, conforme leciona Jürgen Habermas, "como alternativa à subordinação do direito ao direito natural, 
recomenda-se abordar o direito positivo exigível como um complemento funcional da moral, pois ele aliva as pessoas que devem agir e julgar, tomando-lhes o fardo das exigências cognitivas, motivacionais e organizatórias de uma moral ligada à consciência subjetiva" (HABERMAS, 2003, p. 313). No sistema codificado especificamente, aqui focado em razão de ser o mais avançado estruturalmente e efetivamente adotado no cenário brasileiro, a primeira manifestação segura do Direito surge através da redação escrita dos postulados éticos, que passaram a ser plasmados em legislação reforçada pela autoridade pública, de modo a se tornarem critérios decisórios prevalecentes (HABERMAS, 2003. p. 151).

Outrossim, o Direito representa um aperfeiçoamento na fixação de padrões deliberativos, na medida em que firma as políticas públicas e as ponderações de valores dos líderes de determinado grupo em um corpo identificável, de modo a conferir mais segurança quanto à previsibilidade das consequências das decisões praticadas pelas pessoas, cuja eficácia é assegurada mediante o estabelecimento de estruturas políticas para imposição de consequências com emprego da força, acaso necessário.

Notadamente, a Moral é uma apreciação puramente subjetiva e de difícil aferição, de modo a se tornar historicamente necessária a convergência dos critérios morais em uma Ética intersubjetiva, que é mais ampla e perceptível, porquanto compartilhada em grupos específicos. Porém, os parâmetros éticos carecem de uma estrutura estatal que firme os postulados de forma indelével e os reforce institucionalmente, ainda que mediante o emprego da força, características estas que o Direito assumiu. No ponto, cabe novamente invocar os argumentos de Jürgen Habermas, no sentido de que, "quanto maior for a complexidade da sociedade e quanto mais se ampliar a perspectiva restringida etnocentricamente, tanto maior será a pluralização das formas de vida, as quais inibem zonas de sobreposição ou de convergência de convicções que se encontram na base do 
mundo da vida", de modo a estimular que, "em sociedades organizadas em forma de Estado, a ordem normativa natural é reformulada em normas do direito" (HABERMAS, 2003, p. 44-45).

\section{RELAÇÃO ENTRE MORAL, ÉTICA E DIREITO}

De acordo com a abordagem acima exposta, é possível concluir que as três esferas em análise estão intrinsecamente interligadas, numa confluência inseparável, não só pela gradação histórica de passagem de uma para a outra, ao longo do progresso civilizatório, mas também pelas características complementares entre si.

A Moral reflete a pauta valorativa de cada pessoa, que serve de critério de julgamento inafastável, haja vista que, como já dito, o intérprete não tem como blindar suas operações mentais com relação aos próprios preconceitos (ou pré-conceitos) que emprega como base deliberativa.

A Ética, de outro lado, representa os valores sociais fluídos dentro de determinado grupo, cuja importância é determinante para fixação das políticas públicas a serem implementadas, pois estas são reflexivas das opiniões axiológicas compartilhadas em Sociedade. Cabe referir que a eticidade pode viger em uma corporação, em uma cidade e, mesmo, em um país inteiro (sendo discutível, ainda, a existência de padrões éticos mundialmente compartilhados), embora quanto maior a população abrangida, menor tende a ser a área de convergência de opiniões axiológicas.

E, por fim, o Direito representa o instituto imprescindível para orientação das decisões em Sociedade, porquanto consubstancia a fixação segura das políticas públicas a serem promovidas e dos padrões axiológicos prevalecentes em determinada comunidade, plasmados em um corpo unificado (geralmente, em textos legislativos ou em precedentes judiciais) e passíveis de adjudicação forçada institucionalmente, em caso de inobservância (HABERMAS, 2003, p. 97). 
Conforme Jürgen Habermas, "as instituições jurídicas distinguem-se de ordens institucionais naturais através de seu elevado grau de racionalidade; pois nelas, se incorpora um sistema de saber mantido dogmaticamente, isto é, articulado, trazido para um nível científico e interligado com uma moral conduzida por princípios" (HABERMAS, 2003, p. 111).

Cada uma das ordens de conduta não pode existir sem a outra, como uma relação complementar inafastável. Tal confluência decorre, a um, da mencionada relação derivativa, na medida em que uma origina a outra, partindo da moralidade, passando pela eticidade e, por fim, chegando à juridicidade, consoante a abordagem histórica antes exposta. A dois, também porque as referidas esferas são reciprocamente condicionantes, na medida em que aquilo tido por cada pessoa como correto (moralidade) é determinante para deliberar quais os valores e interesses convergentes dos grupos sociais majoritários e minoritários (eticidade), os quais, consequentemente, acabam influenciando as autoridades públicas na redação dos Textos Normativos (juridicidade). E tal condicionamento também faz o sentido inverso, haja vista que a interpretação da legislação, por via reflexiva, também influencia o que cada um entende por certo e justo, de modo a estabelecer um refluxo da juridicidade sobre a eticidade e a moralidade. E, a três, porque todas as três categorias são voltadas ao direcionamento das decisões em Sociedade, tanto para permitir a previsibilidade de determinadas condutas, como para estabelecer as consequências quanto à observância ou não dos postulados morais, éticos e jurídicos.

Daí ser "possível provar, sob pontos de vista funcionais, por que a estrutura pós-tradicional de uma moral orientada por princípios depende de uma complementação através do direito positivo" (HABERMAS, 2003, p. 23).

Ademais, a fixação de postulados jurídicos dificilmente se sustenta sem que esteja efetivamente lastrada na percepção da moralidade e da eticidade compartilhada pelo grupo social, haja vista que haverá uma tendência de descumprimento, em 
razão da convicção de que não representa os valores socialmente importantes. De outro lado, um preceito normativo que tenha sido fixado pelo legislador refletindo estreitamente os interesses amplamente prevalecentes no contexto social, certamente terá maior aceitação espontânea (POSNER, 2007, p. 299). Ora, "uma moral dependente de um substrato de estruturas da personalidade ficaria limitada em sua eficácia, caso não pudesse atingir os motivos dos agentes por um outro caminho, que não o da internalização, ou seja, o da institucionalização de um sistema jurídico que complementa a moral da razão do ponto de vista da eficácia para a ação" (HABERMAS, 2003, p. 149-150).

\section{CONCLUSÃO}

Em síntese, a Moral reflete a escala de valores de cada pessoa, voltada ao direcionamento daquilo que é certo ou errado (justo ou injusto), de acordo com seu conhecimento adquirido, de modo a orientar as suas deliberações. A Ética consiste no conjunto de parâmetros valorativos convergentes em determinado grupo de pessoas ou comunidade individualmente identificável, de modo a orientar e delimitar as deliberações tomadas perante o agrupamento. E o Direito é o instituto artificialmente criado para cristalizar os parâmetros morais e éticos de tomada de decisão e para fixar as consequências quanto à sua observância ou não, as quais são reforçadas institucionalmente, mediante estruturas políticas criadas para esta finalidade.

$\mathrm{Tal}$ conceito operacional deixa claro que a ligação intrínseca do Direito é efetivamente com a Decisão Jurídica, porquanto se trata de um conjunto prevalecente de direcionamentos de cunho moral e ético, reduzido a uma forma linguística, para orientar condutas, de modo a conferir segurança aos integrantes do grupo social (certeza jurídica). O caráter coativo, outrora tido como central à definição, é apenas uma condição para sua eficácia social global, sob pena de se tornar inócuo, haja vista que as consequências artificialmente fixadas no sistema 
jurídico não são uma decorrência natural do descumprimento dos padrões decisórios, demandando um esforço institucional de implementação, de modo a estimular a observância generalizada (GÜNTHER, 2004, p. 365).

Ou seja, os juspositivistas clássicos estavam errados não só porque Direito é muito mais Decisão do que coação, mas também porque este se encontra permanentemente ligado, numa relação complexa e reflexiva, com a Moral e com a Ética.

Portanto, aqui se apresenta esta versão da correlação entre Moral, Ética e Direito, para que sirva de base para construção de um novo modelo disciplinar, superador da abordagem juspositivista, em seus aspectos descritivo e prescritivo, nos termos antes expostos.

\begin{abstract}
This paper proposes new concepts of Morality and Ethics, in order to clarify the understanding of political morality and thus enable a more appropriate description of it's confluence within Legal Theory.
\end{abstract}

Keywords: Morality. Ethics. Legal Theory.

\title{
REFERÊNCIAS
}

ALEXY, Robert. Conceito e validade do direito. Tradução de: Gercelia Batista de Oliveira Mendes. São Paulo: Martins Fontes, 2009. Título original: Begriff un Geltung des Rechts.

DIMOULIS, Dimitri. Positivismo jurídico: introdução a uma teoria do direito e defesa do pragmatismo jurídico-político. São Paulo: Método, 2006.

DWORKIN, Ronald. Justice for hedgehogs. Cambridge-MA: The Belknap Press of Harvard University Press, 2011.

Levando os direitos a sério. Tradução de: Nelson Boeira. 2 ed. São Paulo: Martins Fontes, 2007. Título original: Taking rights seriously.

Uma questão de princípio. Tradução de: Luís Carlos Borges. 2 ed. São Paulo: Martins Fontes, 2005. Título original: A matter of principle. 
GÜNTHER, Klaus. Teoria da argumentação no direito e na moral: justificação e aplicação. Tradução de: Claudio Molz. São Paulo: Landy, 2004. Título original: Der Sinn fur Angemessenheit: Anwendungsdiskurse in Moral und Recht.

HABERMAS, Jürgen. Direito e democracia: entre facticidade e validade. V 1. Tradução de: Flávio Beno Siebeneichler. Rio de Janeiro: Tempo Brasileiro, 2003. Título original: Faktizität und Geltung: beiräge zur Diskurstheorie des Rechts und des demokratischen Rechitstaats.

. Direito e democracia: entre facticidade e validade. V 2. Tradução de: Flávio Beno Siebeneichler. Rio de Janeiro: Tempo Brasileiro, 2003. Título original: Faktizität und Geltung: beiräge zur Diskurstheorie des Rechts und des demokratischen Rechitstaats.

HART, H. L. A. O conceito de direito. Tradução de: Antônio de Oliveira Sette-Câmara. São Paulo: Martins Fontes, 2009. Título original: The concept of law.

KELSEN, Hans. Teoria pura do direito. 7 ed. Tradução de: João Baptista Machado. São Paulo: Martins Fontes, 2006. Título original: Reine Rechtslehre.

KUHN, Thomas S. A estrutura das revoluções científicas. Tradução de: Beatriz Vianna Boeira e Nelson Boeira. São Paulo: Perspectiva, 2009. Título original: The structure of cientific revolutions.

MEZZAROBA, Orides. MONTEIRO, Cláudia Servilha. Manual de metodologia da pesquisa no direito. 3 ed. São Paulo: Saraiva, 2007.

PASOLD, Cesar Luiz. Metodologia da pesquisa jurídica: teoria e prática. 12 ed. rev. São Paulo: Conceito, 2011.

PECES-BARBA, Gregorio. FERNÁNDEZ, Eusebio. ASÍS, Rafael de. Curso de teoría del derecho. 2 ed. Madrid: Marcial Pons, 2000.

POSNER, Richard Allen. Fronteiras da teoria do direito. Tradução de: Evandro Ferreira e Silva, Jefferson Luiz Camargo, Paulos Salles e Pedro Sette-Camara. São Paulo: Martins Fontes, 2011. Título original: Frontiers of legal theory.

ZANON JUNIOR, Orlando Luiz. A centralidade material da constituição. Âmbito Jurídico, Rio Grande, n. 95, 2011. Disponível em: www.ambitojuridico.com.br. Acesso em: 01.12.2011.

. Teoria Complexa do Direito. CEJUR: Florianópolis, 2013. 